OPEN ACCESS

Edited by:

Marilia Seelaender,

University of São Paulo, Brazi

Reviewed by:

Meghit Boumediene Khaled, University of Sidi-Bel-Abbès, Algeria Antonio Caputi,

University of Bari Aldo Moro, Italy

*Correspondence:

Mohammad A/

m180002@student.bup.edu.bd

Specialty section:

This article was submitted to

Clinical Nutrition,

a section of the journal

Frontiers in Nutrition

Received: 31 May 2021 Accepted: 10 September 2021 Published: 05 October 2021

Citation: Ali M, Uddin Z and Hossain A (2021) Combined Effect of Vitamin $D$ Supplementation and Physiotherapy on Reducing Pain Among Adult Patients With Musculoskeletal Disorders: A Quasi-Experimental Clinical Trial. Front. Nutr. 8:717473. doi: 10.3389/fnut.2021.717473

\section{Combined Effect of Vitamin D Supplementation and Physiotherapy on Reducing Pain Among Adult Patients With Musculoskeletal Disorders: A Quasi-Experimental Clinical Trial}

\author{
Mohammad Ali ${ }^{1,2 *}$, Zakir Uddin ${ }^{3}$ and Ahmed Hossain ${ }^{4,5}$ \\ ${ }^{1}$ Department of Physiotherapy and Rehabilitation, Uttara Adhunik Medical College and Hospital, Dhaka, Bangladesh, ${ }^{2}$ Hasna \\ Hena Pain, Physiotherapy and Public Health Research Center, Dhaka, Bangladesh, ${ }^{3}$ School of Rehabilitation Sciences, \\ McMaster University, Hamilton, ON, Canada, ${ }^{4}$ Department of Public Health, North South University, Basundhara, Dhaka, \\ Bangladesh, ${ }^{5}$ North South University (NSU) Global Health Institute, Basundhara, Dhaka, Bangladesh
}

Background: The prevalence of musculoskeletal disorders (MSD) and vitamin D insufficiency is high. Past research indicating vitamin D supplementation and physiotherapy are useful for the treatment of MSDs. However, to the best of our knowledge, the combined benefits of vitamin $D$ and physiotherapy are not yet evaluated in MSD. We hypothesized that combined intervention of vitamin D supplementation and physiotherapy would be more effective in relieving the pain of MSD compared to only physiotherapy intervention.

Objective: This study aimed to examine whether combined effect of vitamin D supplementation and physiotherapy was better than physiotherapy alone in reducing pain-related outcomes (e.g., pain severity, affective interference, and physical interference) in patients with MSD.

Methods: A quasi-clinical experiment was conducted between May 2020 and April 2021. Vitamin D level in the blood was measured at the start of the study. Patients with vitamin D levels $<20 \mathrm{ng} / \mathrm{mL}$ were assigned to the combined physiotherapy and vitamin $\mathrm{D}$ group. The physiotherapy group consisted of the patients with vitamin $\mathrm{D}$ levels more than $20 \mathrm{ng} / \mathrm{mL}$. The Brief Pain Inventory scale was utilized to measure pain at baseline and after 12 weeks of interventions. We used the paired $t$-tests for unadjusted analysis. Further, a linear regression model was used to identify the combined effect of physiotherapy and vitamin D on reducing pain scores after adjusting potential confounders.

Results: Combined intervention of vitamin D and physiotherapy showed significantly better results than only physiotherapy intervention in the reduction of three pain-related outcomes $(p<0.001)$. The multivariable analysis indicated that the combination of physiotherapy and vitamin $D$ treatment reduced pain score by 1.126 (slope $=-1.126, p=0.035$ ) compared to physiotherapy alone. 
Conclusion: Combined intervention (vitamin D with physiotherapy) had a better pain-relieving effect than physiotherapy alone. To confirm these findings, more research is needed with randomized control trials.

Clinical Trial Registration: [http://ctri.nic.in/Clinicaltrials/advancesearchmain.php], identifier [CTRI/2020/04/024845].

Keywords: clinical trial, combined therapy, musculoskeletal disorder, physiotherapy, vitamin D, quasiexperimental design

\section{INTRODUCTION}

According to the Global Burden of Disease study 2019, 1.7 billion people worldwide exhibit musculoskeletal disorders (MSD), which is the leading cause of disability (1). Low back pain (LBP) is the most common symptom of MSD, followed by neck pain, fractures, traumas, and osteoarthritis. The global point prevalence of activity-limiting single MSD (i.e., LBP) in 2015 was $7.3 \%$, implying that 540 million people were affected by LBP at any one moment of life (2).

Furthermore, the world population has a significant frequency of serum 25-hydroxyvitamin D $(25(\mathrm{OH})$ D) (vitamin D) deficiency. Vitamin D deficiency affects 24\% Americans, 37\% Canadians, and 40\% Europeans; in India, 490 million people exhibit vitamin D deficiency (3). Vitamin D deficiency can affect up to $99 \%$ of people depending on their age and ailments (3). In Bangladesh, the incidence of vitamin $\mathrm{D}$ deficiency among various groups of individuals is as high as $100 \%(4-6)$.

A positive association between vitamin D deficiency and the leading MSD, such as LBP, neck pain, and knee pain, among others has been indicated. A triple-arm controlled study suggested that severe vitamin $\mathrm{D}$ deficiency is associated with sub-acute and chronic LBP (7). A systematic review and metaanalysis of observational studies concluded that vitamin D deficiency is significantly associated with LBP (8). Other studies also revealed the association between vitamin $\mathrm{D}$ deficiency and neck pain $(9,10)$. Furthermore, there is a remarkable association between vitamin D deficiency and knee pain (11). In general, the association between vitamin D deficiency and MSD (e.g., arthritis, muscle pain, and chronic widespread pain) is wellknown (12).

Despite having a variety of options, managing MSD can be difficult and expensive; nonetheless, the results of any given treatment are not always adequate and are not recommended for universal usage $(13,14)$. Supplementation of vitamin D is a cost-effective treatment option for patients with MSD and a systematic review summarized that vitamin D supplementation can decrease pain scores and improve pain; however, no statistically significant change in the visual analog scale of pain intensity has been observed (15). On the other hand, physiotherapy interventions have frequently been used for treating MSD conditions, such as LBP, neck pain, shoulder pain, and knee pain, and numerous

Abbreviations: MSD, musculoskeletal disorders; LBP, low back pain; BPI, Brief Pain Inventory. studies found physiotherapy interventions effective $(16,17)$. Nonetheless, it is hypothesized that the combination of both physiotherapy interventions and vitamin $\mathrm{D}$ supplementation can be more effective for patients with MSD than a single intervention. To the best of our knowledge, no study has examined the combined effect of physiotherapy and vitamin D supplementation among patients with MSD. Therefore, the primary goal of this clinical investigation was to evaluate if vitamin $\mathrm{D}$ supplementation in addition to physiotherapy may significantly reduce pain intensity, affective interference, and physical interference in adult patients with MSD.

\section{MATERIALS AND METHODS}

\section{Study Participants}

Patients with musculoskeletal pain (LBP, neck pain, shoulder pain, and knee pain) aged 24-80 years who sought physiotherapy treatment at the physiotherapy and rehabilitation departments of Uttara Adhunik Medical College and Hospital in Dhaka and Hasna Hena Pain and Physiotherapy and Public Health Research Center in Dhaka city were randomly selected for this study. Patients under the age of 18 years and those who were experiencing pain because of cancer or tuberculosis were excluded from the study. Patients who did not adhere to the treatment plan or who desired to withdraw from the research were also excluded. Two hundred patients were eligible for the study based on the inclusion and exclusion criteria. We approached 150 people to ask whether they wanted to participate in the study, and 143 of them agreed. Eight patients later dropped out of the research. After 12-weeks, 135 patients finally gave data for the study. The flow chart has been presented in Figure 1.

\section{Study Design}

This was a clinical trial using a quasi-experimental design. Data were collected at baseline and 12 weeks after the intervention between May 2020 and April 2021. Participants who gave their consent and met the inclusion criteria were interviewed using the Brief Pain Inventory (BPI) scale to record pain levels at baseline and after 12 weeks of pain relief intervention. Patients were also examined for vitamin D, hemoglobin, and nutrition levels. Following a standard protocol, a blood sample was collected from patients at the Uttara Adhunik Medical College and Hospital's Department of Pathology and Biochemistry. 
Visited musculoskeletal pain patients who were approached for the clinical trial $(\mathrm{n}=15 \mathrm{O})$

Provided consent to be included in the study $(\mathrm{n}=143)$

\section{Dropped out from} the study $(n=4)$

Data after 12 weeks $(n=72)$

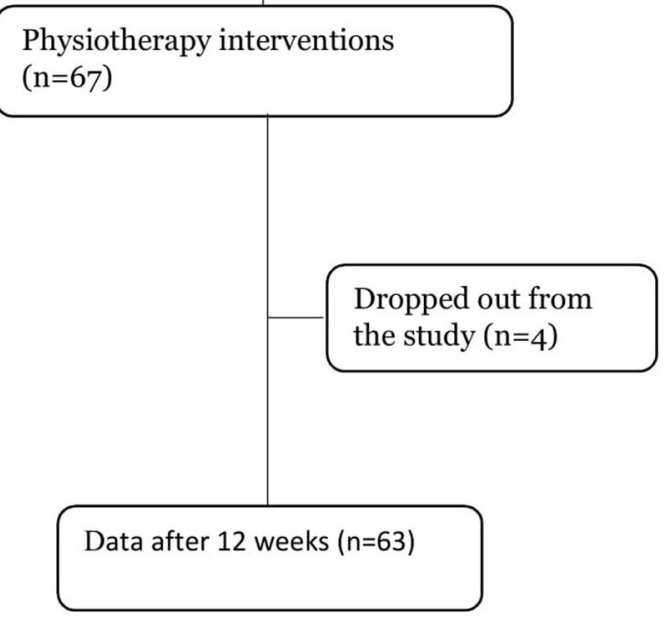

FIGURE 1 | Flow chart of patients' selection.

\section{Measurements}

BPI

\section{Pain Severity}

The pain severity subscale of BPI was used to measure selfreported overall pain severity. The pain severity subscale consists of four items that inquire for worst, least, and average pain intensity ratings within the last 24 -h in addition to present pain ratings. Pain intensity is rated using an 11-point numerical rating scale in which 0 indicates "no pain" and 10 indicates "pain as bad as you can imagine." An overall pain severity rating is calculated as a mean of the four items on pain intensity. The BPI is an internally consistent (Cronbach alpha $=0.82$ ), reliable, and valid measure of pain severity and pain interference for people with musculoskeletal pain (18).

\section{Pain Affective Interference}

The BPI pain interference subscale consists of seven items that assess the extent to which pain interferes with the mood, relations with other people, and enjoyment of life (19). Responses are bounded by 0 (does not interfere) and 10 (interferes completely). Scores on pain affective interference were calculated as an average of their respective items.

\section{Pain Physical Interference}

Consistent with previous work, the physical interference subscale was calculated from BPI scale items relating to how pain interferes with a person's engagement in general activity, walking, and normal work-related activities (20). The three items in the subscale are designed to specifically quantify the degree to which pain interferes in activity engagement. Items are scored on an 11point numerical rating scale $(0-10)$, in which greater disruption to activity engagement due to pain is indicated by higher scores.

The physical and affective factor's items of BPI are supported by confirmatory factor and Rasch analysis (19, 20). Pain interference types (affective and physical) are helpful to guide clinical assessment in pain conditions (21-23). The BPI is widely used for people living with pain and is recommended for painrelated outcome measures (18-21, 24-26).

\section{Nutritional Status \\ Mini Nutritional Assessment Scale}

The mini nutritional assessment is a validated instrument initially developed to assess nutritional status in adult patients and is mainly indicated for research settings $(27,28)$. The tool contains 18 items and evaluates four different aspects: anthropometric assessment (body mass index, weight loss, and arm and calf circumferences); general assessment (lifestyle, medication, mobility, and presence of signs of depression or dementia); short dietary assessment (number of meals, food, and fluid intake and autonomy of feeding); and subjective assessment (self-perception of health and nutrition). After addition of the scores, labeled 
TABLE 1 | Baseline characteristics of the patients.

\begin{tabular}{|c|c|c|c|c|}
\hline \multirow[t]{2}{*}{ Variable } & \multirow[t]{2}{*}{ All (\%) } & \multicolumn{2}{|c|}{ Interventions } & \multirow[t]{2}{*}{$p$-value* } \\
\hline & & $\begin{array}{c}\text { Physiotherapy } \\
\text { + Vitamin D } \\
(\%)\end{array}$ & $\begin{array}{c}\text { Physiotherapy } \\
\text { (\%) }\end{array}$ & \\
\hline \multicolumn{5}{|l|}{ Gender } \\
\hline Female & $91(63.6)$ & $50(54.9)$ & $41(45.1)$ & 0.569 \\
\hline Male & $52(36.4)$ & $26(50)$ & $26(50)$ & \\
\hline \multicolumn{5}{|l|}{ Age group } \\
\hline$\leq 40$ years & $38(26.6)$ & $22(57.9)$ & $16(42.1)$ & 0.065 \\
\hline $41-60$ years & $66(46.2)$ & $40(60.6)$ & $26(39.4)$ & \\
\hline$\geq 60$ years & $39(27.2)$ & $14(35.9)$ & $25(64.1)$ & \\
\hline \multicolumn{5}{|l|}{ BMI group } \\
\hline Normal & 56 (39.2) & $24(42.9)$ & $32(57.1)$ & 0.125 \\
\hline Overweight/obese & $87(60.8)$ & $52(59.8)$ & $35(40.2)$ & \\
\hline \multicolumn{5}{|c|}{ Had walking/exercise habit } \\
\hline No & $96(67.1)$ & $55(57.3)$ & $41(42.7)$ & 0.363 \\
\hline Yes & $47(32.9)$ & $21(44.7)$ & $26(55.3)$ & \\
\hline \multicolumn{5}{|l|}{ Diabetes group } \\
\hline No & $108(75.5)$ & $57(52.8)$ & $51(47.2)$ & 0.877 \\
\hline Yes & $35(24.5)$ & $19(54.3)$ & $16(45.7)$ & \\
\hline \multicolumn{5}{|c|}{ Hypertension group } \\
\hline No & $80(55.9)$ & $47(58.8)$ & $33(41.3)$ & 0.130 \\
\hline Yes & $63(44.1)$ & $29(46.0)$ & $34(54.0)$ & \\
\hline \multicolumn{5}{|c|}{ Hemoglobin level (g/dl) } \\
\hline Risk of anemia & $74(51.7)$ & $42(56.8)$ & $32(43.2)$ & 0.879 \\
\hline Normal range & $69(48.3)$ & $34(49.3)$ & $35(50.7)$ & \\
\hline \multicolumn{5}{|l|}{ Nutrition level } \\
\hline $\begin{array}{l}\text { Risk of } \\
\text { malnourishment }\end{array}$ & $78(49.0)$ & $39(50.0)$ & $39(50.0)$ & 0.537 \\
\hline Nourished & $65(54.5)$ & 37 (56.9) & $28(43.1)$ & \\
\hline \multicolumn{5}{|l|}{ Main complaints } \\
\hline Low back pain & $72(50.3)$ & $38(52.8)$ & $34(47.2)$ & 0.166 \\
\hline Neck pain & $31(21.7)$ & $21(67.7)$ & $10(32.3)$ & \\
\hline Shoulder pain & $16(11.2)$ & $8(50.0)$ & $8(50.0)$ & \\
\hline Knee pain & $24(16.8)$ & $9(37.5)$ & $15(62.5)$ & \\
\hline \multicolumn{5}{|l|}{ Pain duration } \\
\hline$\leq 6$ weeks & $6746.9)$ & $32(47.8)$ & $35(52.2)$ & 0.099 \\
\hline 7-11 weeks & $8(5.6)$ & $7(87.5)$ & $1(12.5)$ & \\
\hline$\geq 12$ weeks & $68(47.6)$ & $37(54.4)$ & 31 (45.6) & \\
\hline
\end{tabular}

* $p$-value was calculated from chi-square test.

as Mini Nutritional Assessment-Long Form, individuals can be divided into three groups using threshold values of $<17$ for "malnourished," 17-23.5 for "at risk of malnutrition," and $\geq 24$ for "normal nutritional status," with a maximum total score of 30 points (29).

\section{Vitamin D Level}

Serum 25(OH)D was used to evaluate the vitamin D status among the study participants. The laboratory analysis was conducted at the Department of Biochemistry, Uttara Adhunik Medical College and Hospital. The serum concentration of $25(\mathrm{OH}) \mathrm{D}$ was measured by chemiluminescence microparticle immunoassay
(ARCHITECT i 1000 SR, USA). Patients were classified based on vitamin D levels as deficient $(<20 \mathrm{ng} / \mathrm{mL})$; insufficient $(20-$ $30 \mathrm{ng} / \mathrm{mL})$; and sufficient $(>30-100 \mathrm{ng} / \mathrm{mL})(6,30)$.

\section{Hemoglobin Level}

A hematology analyzer (Sysmex XN-1000, Japan) was used to estimate the concentration of hemoglobin in the blood. Patients with hemoglobin levels between the ranges of $13-18 \mathrm{~g} / \mathrm{dL}$ were considered normal.

\section{Patient Grouping and Interventions}

The participants were distributed into two groups according to their vitamin D levels: physiotherapy and physiotherapy + vitamin $\mathrm{D}$ groups. The physiotherapy group consisted of patients who had vitamin D levels $\geq 20 \mathrm{ng} / \mathrm{mL}$. Rest of the patients (vitamin D level $<20 \mathrm{ng} / \mathrm{mL}$ ) were included in the physiotherapy + vitamin $\mathrm{D}$ group. All the patients were given traditional physiotherapy interventions for a maximum of 21 sessions. However, only the physiotherapy + vitamin D group was given a 40,000 IU vitamin D3 capsule made by a specific pharmaceutical company of Bangladesh per week for 8 weeks. To ensure the correct dose, patients were asked to visit the Uttara Adhunik Medical College and Hospital or Hasna Hena Pain and Physiotherapy and Public Health Research Center to take the capsule on full stomach at afternoon every week. A card with a chart of capsule-taking dates was maintaining to avoid any misconduct. Although there are no reported adverse effects of physiotherapy and vitamin D supplementation, the contact number of a physiotherapist and physician were given to the participants in case of any emergency or concern. Data were collected at the baseline and after 12 weeks.

\section{Ethics and Trial Registration}

The study was conducted following the ethical standards outlined in the Helsinki Declaration (1983). The Ethics Review Committee of Uttara Adhunik Medical College and Hospital approved the study. This clinical trial was registered prospectively from World Health Organization endorsed Clinical Trials Registry CTRI/2020/04/024845, Registered on 24/04/2020, http://ctri. nic.in/Clinicaltrials/advancesearchmain.php. All participants provided written consent.

\section{Statistical Analysis}

The acquired data were entered into the IBM SPSS 21 program (SPSS Inc., Chicago, IL, USA), and the statistical analysis was completed with $\mathrm{R}$ 3.6.3. The arithmetic mean and standard deviation (SD) were used to describe the continuous variables. Frequency and percentage were used to express categorical variables. For categorical variables, the chi-square and Fisher's exact tests were employed to determine the difference between the groups. Before and after the evaluation, the withingroup comparisons were determined using a paired samples $t$-test. The results were assessed using a 95\% confidence interval. Finally, after adjusting for sex and age group, a multivariable linear regression model was conducted to examine 
the combined effect of vitamin D and physiotherapy on change in pain scores.

\section{RESULTS}

This quasi-experimental study included 143 patients (mean \pm SD age, $51.2 \pm 13.3$ years; range $24-80$ years; $63.6 \%$ women). Table 1 provides the baseline results of the participants. At baseline, there were no significant differences between the two groups in terms of sex $(p=0.569)$, age $(p=0.065)$, body mass index $(p=$ $0.125)$, exercise habit $(p=0.363)$, diabetes mellitus $(p=0.877)$, hypertension $(p=0.130)$, hemoglobin level $(p=0.879)$, nutrition level $(p=0.537)$, main complaints $(p=0.166)$, and pain duration $(p=0.811)$.

Figures 2-4 display the improvement in pain score after receiving the combination of vitamin $\mathrm{D}$ and physiotherapy treatment, and only physiotherapy intervention. In these figures (Figures 2-4) of pain severity, affective interference, and physical interference, the combination of vitamin D and physiotherapy treatment resulted in a significant reduction in pain scores compared to only physiotherapy intervention.

The descriptive results of changes in pain scores between before and after interventions are shown in Table 2. In comparison to the physiotherapy intervention, the combination of physiotherapy and vitamin $D$ treatment resulted in a significant reduction in pain severity score $(p=0.001)$, affective interference score $(p=0.001)$, and physical interference score $(p=0.001)$.

The findings of a multivariable linear regression model adjusted for sex and age are presented in Table 3 . The findings revealed that age and sex had no effect on the reduction of overall

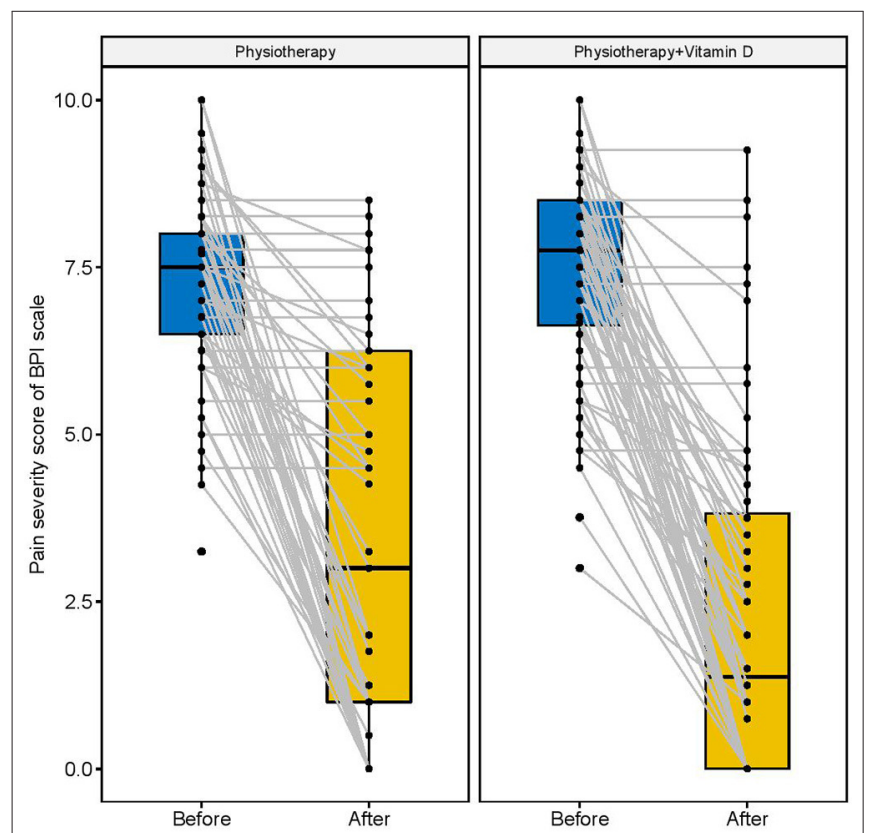

FIGURE 2 | Pain intensity scores before and after intervention among both groups. pain in patients with MSD. When compared to physiotherapy intervention alone, the combination of physiotherapy and vitamin $\mathrm{D}$ treatment reduced pain score by 1.126 (slope $=$ $-1.126, p=0.035)$.

\section{DISCUSSION}

The study shows irrespective of all measured potential confounders, vitamin D3 supplementation in addition to

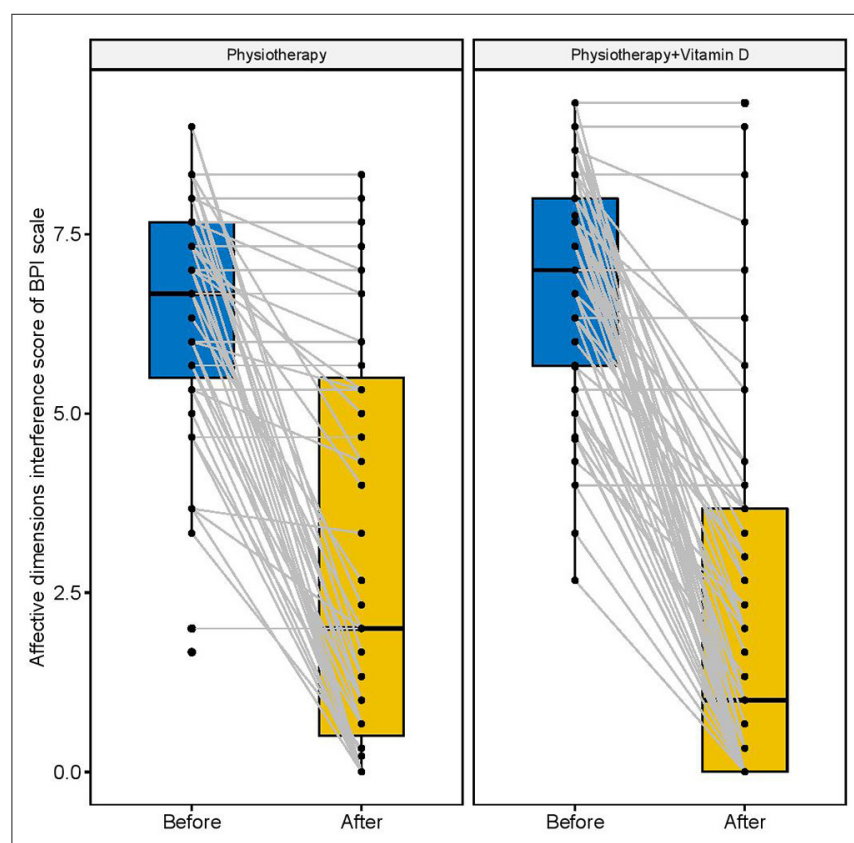

FIGURE 3 | Physical interference scores before and after the intervention.

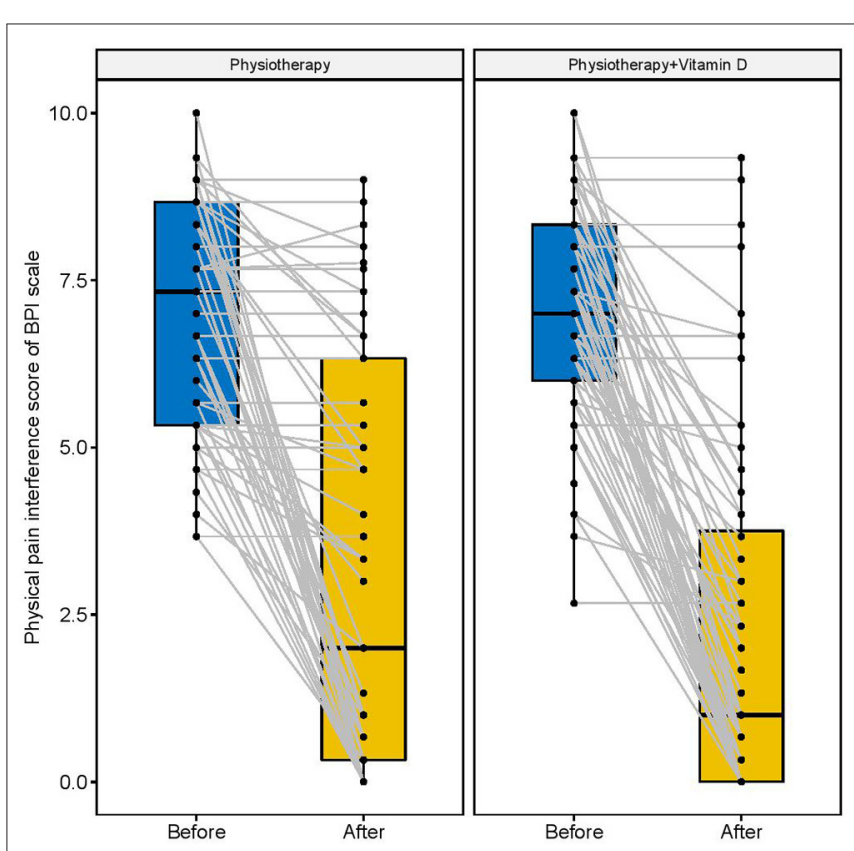

FIGURE 4 | Affective interference scores before and after the intervention. 
TABLE 2 | Change of pain score (mean difference before and after intervention) among physiotherapy + Vitamin D and Physiotherapy group after 12-week.

\begin{tabular}{|c|c|c|c|c|c|}
\hline \multirow[t]{2}{*}{ Pain category } & \multicolumn{2}{|c|}{ Physiotherapy + Vitamin D } & \multicolumn{2}{|c|}{ Physiotherapy } & \multirow[t]{2}{*}{$p$-value* } \\
\hline & Mean difference & $95 \% \mathrm{Cl}$ & Mean difference & $95 \% \mathrm{Cl}$ & \\
\hline Pain severity score & -4.92 & $-5.57,-4.26$ & -3.79 & $-4.58,-3.01$ & $<0.001$ \\
\hline Affective interference score & -4.63 & $-5.26,-3.99$ & -3.46 & $-4.20,-2.72$ & $<0.001$ \\
\hline Physical Interference score & -4.75 & $-5.36,-4.14$ & -3.80 & $-4.63,-2.96$ & $<0.001$ \\
\hline
\end{tabular}

Cl, Confidence Interval.

${ }^{*} p$-value was calculated from the t-test.

TABLE 3 | Multivariable linear regression analysis on an overall change of pain score.

\begin{tabular}{lll}
\hline Variable & $\begin{array}{c}\text { Slope of } \\
\text { change score }\end{array}$ & Standard error $p$-value \\
\hline
\end{tabular}

Gender
Female
Male
Age group
$\leq 40$
$41-60$
$\geq 60$

Intervention group

Physiotherapy Reference

Physiotherapy + Vitamin D $\quad-1.126$

*Significant at 5\% significance level.

physiotherapy was significantly effective in reduction of pain severity and affective and physical interface. This novel finding provides a scientific basis on the role of vitamin D in improving musculoskeletal pain outcomes.

To the best of our knowledge, we provide here the first quasi-experimental data of patients with musculoskeletal pain examining the effect of vitamin $\mathrm{D}$ supplementation in addition to physiotherapy compared to only physiotherapy intervention on the reduction of pain parameters (e.g., pain severity, affective pain interference, and physical pain interference). In line with our findings, a systematic review and meta-analysis of published randomized controlled trials suggested that vitamin D supplementation can decrease pain scores significantly (31). Another review also concluded that vitamin D may establish a safe, simple, and potentially beneficial way to reduce pain among patients with vitamin D deficiency (32). However, systematic reviews presented evidence that high vitamin $\mathrm{D}$ concentration in the blood is associated with good cognitive function in adults (33, 34). Regarding physical interference, systematic reviews found inconclusive results $(35,36)$. Previous evidence of the positive impact of physiotherapy on physical activity promotion (37-39) may explain the significant improvement in physical interference among the vitamin $\mathrm{D}+$ physiotherapy group patients.

Our study suggested that the patients with LBP, neck pain, shoulder pain, and knee pain were equally benefited from vitamin
D supplementation along with physiotherapy. Managing one of the major global burdens, that is, LBP is a significant challenge for the clinicians (40). Our study showed that supplementation of vitamin $\mathrm{D}$ along with physiotherapy provides better efficacy compared to physiotherapy alone when managing LBP. A systematic review and meta-analysis published in 2017 concluded that there is an inconsistent association between vitamin $\mathrm{D}$ deficiency and LBP (8). Similarly, another systematic review of clinical trials indicated that vitamin D supplementation was not more effective than placebo in LBP (41). Evidence from our study provides a scientific clue to use vitamin D supplementation as a combined therapy when managing LBP for best results. Additional randomized control trials are warranted to conclude this result.

A systematic review has revealed the beneficial effect of vitamin D supplementation when treating neck pain (10). Similarly, a higher prevalence of hypovitaminosis D has been found in patients with knee and shoulder pain (9, 11, 42). Additional randomized control trials are required to further evaluate the effect of vitamin D supplementation among patients with neck, shoulder, and knee pain.

The association between hypovitaminosis $\mathrm{D}$ and poor health outcome is well-known; however, the relationship between vitamin $\mathrm{D}$ and chronic pain is not clear yet. Furthermore, the mechanism by which vitamin $\mathrm{D}$ inhibits chronic pain development is still ambiguous. In light of the current lack of evidence, supplementation of vitamin $\mathrm{D}$ cannot be recommended as an effective independent treatment for chronic pain (43). However, for better treatment of chronic pain, vitamin $\mathrm{D}$ in combination with other treatments is beneficial (44). In our study, we found better efficacy in chronic pain management when vitamin $\mathrm{D}$ was used with physiotherapy. On the other hand, limited information is available regarding the effectiveness of vitamin $\mathrm{D}$ for acute and sub-acute pain management; however, our study found similar efficacy for chronic pain management when treated with vitamin D and physiotherapy.

\section{Strength of the Study}

The strength of the study includes (1) sufficient number of patients recruited for both the vitamin $\mathrm{D}+$ physiotherapy and physiotherapy groups; (2) equal distribution of patients for each sub-group, for example, sex, age group, chief complaints, and pain duration; and (3) the standardized collection of data and pathological tests from a single research center. 


\section{Limitations of the Study}

There were three limitations of this study. First, our study's quasi-experimental methodology was less reliable than a randomized controlled trial. Second, we included patients with the combination of vitamin $\mathrm{D}$ and physiotherapy treatment for vitamin $\mathrm{D}$ deficient patients, which may have influenced the pain score. Third, because of cost constraints, vitamin D concentration from blood was not tested after 12 weeks of intervention in this study.

In conclusion, this study gives information on the future possible use of vitamin $\mathrm{D}$ supplementation in the treatment of patients with MSD when used in conjunction with physiotherapy. Combined intervention (vitamin D with physiotherapy) showed significantly better results than only physiotherapy intervention in the reduction of three pain-related outcomes, pain severity, affective interference, and physical interference, in musculoskeletal pain. To confirm these findings, more research is needed, including randomized controlled trials with placebo controls and longer follow-ups.

\section{DATA AVAILABILITY STATEMENT}

The raw data supporting the conclusions of this article will be made available by the authors, without undue reservation.

\section{REFERENCES}

1. Cieza A, Causey K, Kamenov K, Hanson SW, Chatterji S, Vos T. Global estimates of the need for rehabilitation based on the Global Burden of Disease study 2019: a systematic analysis for the Global Burden of Disease Study 2019. Lancet. (2020) 396:2006-17. doi: 10.1016/S0140-6736(20)3 2340-0

2. Hartvigsen J, Hancock MJ, Kongsted A, Louw Q, Ferreira ML, Genevay S, et al. What low back pain is and why we need to pay attention. Lancet. (2018) 391:2356-67. doi: 10.1016/S0140-6736(18)30480-X

3. Courbebaisse M, Alberti C, Colas S, Prié D, Souberbielle JC, Treluyer JM, et al. Vitamin D supplementation in renAL transplant recipients (Vitale): a prospective, multicentre, double-blind, randomized trial of vitamin D estimating the benefit and safety of vitamin D3 treatment at a dose of 100,000 UI compared with a dose of $12,000 \mathrm{UI}$ in renal transplant recipients: study protocol for a double-blind, randomized, controlled trial. Trials. (2014) 15:430. doi: 10.1186/1745-6215-15-430

4. Hossain HT, Islam QT, Khandaker MAK, Ahasan HN. Study of serum vitamin $\mathrm{D}$ level in different socio-demographic population - a pilot study. J Med. (2017) 19:22-9. doi: 10.3329/jom.v19i1.34836

5. Ahmed AS, Haque WMMU, Uddin KN, Abrar FA, Afroz F, Huque $\mathrm{HF}$, et al. Vitamin $\mathrm{D}$ and bone mineral density status among postmenopausal Bangladeshi women. IMC J Med Sci. (2019) 12:44-9. doi: 10.3329/imcjms.v12i2.39660

6. Mahmood S, Rahman M, Biswas SK, Saqueeb SN, Zaman S, Manirujjaman $\mathrm{M}$, et al. Vitamin D and parathyroid hormone status in female garment workers: a case-control study in Bangladesh. BioMed Res Int. (2017) 2017:4105375. doi: 10.1155/2017/4105375

7. Panwar A, Valupadas C, Veeramalla M, Vishwas HN. Prevalence of vitamin $\mathrm{D}$ deficiency in chronic and subacute low back pain patients in India: a triple-arm controlled study. Clin Rheumatol. (2018) 37:1367-74. doi: 10.1007/s10067-017-3798-z

8. Zadro J, Shirley D, Ferreira M, Carvalho-Silva AP, Lamb SE, Cooper C, et al. Mapping the association between vitamin $\mathrm{D}$ and low back pain: a systematic review and meta-analysis of observational studies. Pain Phys. (2017) 20:61140. doi: $10.36076 / \mathrm{ppj} / 2017.7 .611$

\section{ETHICS STATEMENT}

The studies involving human participants were reviewed and approved by Ethical Review Committee (ERC) of Uttara Adhunik Medical College and Hospital. The patients/participants provided their written informed consent to participate in this study.

\section{AUTHOR CONTRIBUTIONS}

MA conceived the idea, designed and conducted the trial, managed the project and participants, interpreted the data, drafted, and review the manuscript. $\mathrm{ZU}$ and $\mathrm{AH}$ supervised the study and review the manuscript. $\mathrm{MA}$ and $\mathrm{AH}$ performed the statistical analysis. All authors contributed to the article and approved the submitted version.

\section{ACKNOWLEDGMENTS}

The authors would like to thank the participants for providing us the data. We are also thankful to Prof. Dr. Mohammed Hyder Ali, MBBS, FCPS (Internal Medicine) for his guideline and for providing medical intervention support.

9. Eloqayli H, Al-Yousef A, Jaradat R. Vitamin D and ferritin correlation with chronic neck pain using standard statistics and a novel artificial neural network prediction model. Br J Neurosurg. (2018) 32:172-6. doi: 10.1080/02688697.2018.1436691

10. Cai C. Treating vitamin D deficiency and insufficiency in chronic neck and back pain and muscle spasm: a case series. Perm J. (2019) 23:18241. doi: 10.7812/TPP/18.241

11. Heidari B, Javadian Y, Babaei M, Yousef-Ghahari BY. Restorative effect of vitamin D deficiency on knee pain and quadriceps muscle strength in knee osteoarthritis. Acta Med Iran. (2015) 53:466-70. Available online at: https://acta.tums.ac.ir/index.php/acta/article/view/4268 (accessed December 27, 2020).

12. Wu Z, Malihi Z, Stewart AW, Lawes CM, Scragg R. The association between vitamin $\mathrm{D}$ concentration and pain: a systematic review and metaanalysis. Public Health Nutr. (2018) 21:2022-37. doi: 10.1017/S1368980018 000551

13. Lin I, Wiles L, Waller R, Goucke R, Nagree Y, Gibberd M, et al. What does best practice care for musculoskeletal pain look like? Eleven consistent recommendations from high-quality clinical practice guidelines: systematic review. Br J Sports Med. (2020) 54:79-86. doi: 10.1136/bjsports-2018-099878

14. Carlson H, Carlson N. An overview of the management of persistent musculoskeletal pain. Ther Adv Musculoskelet Dis. (2011) 3:91-9. doi: 10.1177/1759720X11398742

15. Yong WC, Sanguankeo A, Upala S. Effect of vitamin D supplementation in chronic widespread pain: a systematic review and meta-analysis. Clin Rheumatol. (2017) 36:2825-33. doi: 10.1007/s10067-017-3754-y

16. Desmeules F, Roy JS, MacDermid JC, Champagne F, Hinse O, Woodhouse LJ. Advanced practice physiotherapy in patients with musculoskeletal disorders: a systematic review. BMC Musculoskelet Disord. (2012) 13:107. doi: 10.1186/1471-2474-13-107

17. Babatunde OO, Jordan JL, Van der Windt DA, Hill JC, Foster NE, Protheroe J. Effective treatment options for musculoskeletal pain in primary care: a systematic overview of current evidence. PLoS ONE. (2017) 12:e0178621. doi: 10.1371/journal.pone.0178621

18. Keller S, Bann CM, Dodd SL, Schein J, Mendoza TR, Cleeland CS. Validity of the brief pain inventory for use in documenting 
the outcomes of patients with noncancer pain. Clin J Pain. (2004) 20:309-18. doi: 10.1097/00002508-200409000-00005

19. Walton DM, Beattie T, Putos J, MacDermid JC. A Rasch analysis of the brief pain inventory interference subscale reveals three dimensions and an age bias. J Clin Epidemiol. (2016) 74:218-26. doi: 10.1016/j.jclinepi.2015.10.022

20. Walton DM, Putos J, Beattie T, MacDermid JC. Confirmatory factor analysis of 2 versions of the brief pain inventory in an ambulatory population indicates that sleep interference should be interpreted separately. Scand J Pain. (2016) 12:110-16. doi: 10.1016/j.sjpain.2016.05.002

21. Miettinen T, Kautiainen H, Mäntyselkä P, Linton SJ, Kalso E. Pain interference type and level guide the assessment process in chronic pain: categorizing pain patients entering tertiary pain treatment with the Brief Pain Inventory. PLoS ONE. (2019) 14:e0221437. doi: 10.1371/journal.pone.0221437

22. Uddin Z, Woznowski-Vu A, Flegg D, Aternali A, Wickens R, Wideman TH. Evaluating the novel added value of neurophysiological pain sensitivity within the fear-avoidance model of pain. Eur J Pain. (2019) 23:95772. doi: 10.1002/ejp. 1364

23. Uddin Z, Woznowski-Vu A, Flegg D, Aternali A, Wideman TH. A cumulative impact of psychological and sensitization risk factors on pain-related outcomes. Pain Pract. (2021) 21:523-35. doi: 10.1111/papr.12987

24. Dworkin RH, Turk DC, Farrar JT, Haythornthwaite JA, Jensen MP, Katz NP, et al. Core outcome measures for chronic pain clinical trials: IMMPACT recommendations. Pain. (2005) 113:9-19. doi: 10.1016/j.pain.2004.09.012

25. Osborne TL, Raichle KA, Jensen MP, Ehde DM, Kraft G. The reliability and validity of pain interference measures in persons with multiple sclerosis. $J$ Pain Symptom Manage. (2006) 32:217-29. doi: 10.1016/j.jpainsymman.2006. 03.008

26. Woznowski-Vu A, Uddin Z, Flegg D, Aternali A, Wickens R, Sullivan MJL, et al. Comparing novel and existing measures of sensitivity to physical activity among people with chronic musculoskeletal pain: the Importance of tailoring activity to pain. Clin J Pain. (2019) 35:65667. doi: 10.1097/AJP.0000000000000732

27. Holvoet E, Vanden Wyngaert K, Van Craenenbroeck AH, Van Biesen W, Eloot S. The screening score of Mini Nutritional Assessment (MNA) is a useful routine screening tool for malnutrition risk in patients on maintenance dialysis. PLoS ONE. (2020) 15:e229722. doi: 10.1371/journal.pone. 0229722

28. Kiesswetter E, Pohlhausen S, Uhlig K, Diekmann R, Lesser S, Uter W, et al. Prognostic differences of the mini nutritional assessment short form and long form in relation to 1-year functional decline and mortality in communitydwelling older adults receiving home care. J Am Geriatr Soc. (2014) 62:5127. doi: 10.1111 /jgs. 12683

29. Tsai AC, Chang MZ. Long-form but not short-form Mini-Nutritional Assessment is appropriate for grading nutritional risk of patients on hemodialysis-a cross-sectional study. Int J Nurs Stud. (2011) 48:142935. doi: 10.1016/j.ijnurstu.2011.05.004

30. Holick MF, Binkley NC, Bischoff-Ferrari HA, Gordon CM, Hanley DA, et al. Evaluation, treatment, and prevention of vitamin D deficiency: an endocrine society clinical practice guideline. J Clin Endocrinol Metab. (2011) 96:191130. doi: 10.1210/jc.2011-0385

31. Scragg R, Malihi Z, Stewart AW, Lawes CM, Scragg R. Effect of vitamin D supplementation on pain: a systematic review and meta-analysis. Pain Phys. (2016) 7: 415-27. doi: 10.36076/ppj/2016.19.415

32. Helde-Frankling M, Björkhem-Bergman L. Vitamin D in pain management. Int J Mol Sci. (2017) 18:2170. doi: 10.3390/ijms18102170

33. Annweiler C, Allali G, Allain P, Bridenbaugh S, Schott AM, Kressig RW, et al. Vitamin D and cognitive performance in adults: a systematic review. Eur J Neurol. (2009) 16:1083-9. doi: 10.1111/j.1468-1331.2009.02755.x
34. Balion C, Griffith LE, Strifler L, Henderson M, Patterson C, Heckman G, et al. Vitamin D, cognition, and dementia: a systematic review and meta-analysis. Neurology. (2012) 79:1397-405. doi: 10.1212/WNL.0b013e3182 $6 \mathrm{c} 197 \mathrm{f}$

35. Annweiler C, Schott AM, Berrut G, Fantino B, Beauchet O. Vitamin D-related changes in physical performance: a systematic review. J Nutr Health Aging. (2009) 13:893-8. doi: 10.1007/s12603-009-0248-x

36. Farrokhyar F, Sivakumar G, Savage K, Koziarz A, Jamshidi S, Ayeni OR, et al. Effects of vitamin D supplementation on Serum 25-hydroxyvitamin D concentrations and physical performance in athletes: a systematic review and meta-analysis of randomized controlled trials. Sports Med. (2017) 47:232339. doi: 10.1007/s40279-017-0749-4

37. Abaraogu UO, Edeonuh JC, Frantz J. Promoting physical activity and exercise in daily practice: current practices, barriers, and training needs of physiotherapists in eastern Nigeria. Physiother Can. (2016) 68:3745. doi: 10.3138/ptc.2014-74

38. Jonsson M, Hurtig-Wennlöf A, Ahlsson A, Vidlund M, Cao Y, Westerdahl E. In-hospital physiotherapy improves physical activity level after lung cancer surgery: a randomized controlled trial. Physiotherapy. (2019) 105:43441. doi: 10.1016/j.physio.2018.11.001

39. Lowe A, Gee M, McLean S, Littlewood C, Lindsay C, Everett S. Physical activity promotion in physiotherapy practice: a systematic scoping review of a decade of literature. Br J Sports Med. (2018) 52:1227. doi: 10.1136/bjsports-2016-096735

40. Foster NE, Anema JR, Cherkin D, Chou R, Cohen SP, Gross DP, et al. Prevention and treatment of low back pain: evidence, challenges, and promising directions. Lancet. (2018) 391:236883. doi: 10.1016/S0140-6736(18)30489-6

41. Zadro JR, Shirley D, Ferreira M, Carvalho Silva AP, Lamb SE, et al. Is vitamin D supplementation effective for low back pain? A systematic review and meta-analysis. Pain Phys. (2018) 21:121-45. doi: 10.36076/ppj.2018.2.121

42. Dougherty KA, Dilisio MF, Agrawal DK. Vitamin D and the immunomodulation of rotator cuff injury. J Inflam Res. (2016) 9:123-31. doi: 10.2147/JIR.S106206

43. Martin KR, Reid DM. Is there a role for vitamin $D$ in the treatment of chronic pain? Ther Adv Musculoskelet Dis. (2017) 9:131-5. doi: 10.1177/1759720X17708124

44. Habib AM, Nagi K, Thillaiappan NB, Sukumaran V, Akhtar S. Vitamin D and its potential interplay with pain signaling pathways. Front Immunol. (2020) 11:820. doi: $10.3389 /$ fimmu. 2020.00820

Conflict of Interest: The authors declare that the research was conducted in the absence of any commercial or financial relationships that could be construed as a potential conflict of interest.

Publisher's Note: All claims expressed in this article are solely those of the authors and do not necessarily represent those of their affiliated organizations, or those of the publisher, the editors and the reviewers. Any product that may be evaluated in this article, or claim that may be made by its manufacturer, is not guaranteed or endorsed by the publisher.

Copyright (c) $2021 \mathrm{Ali}$, Uddin and Hossain. This is an open-access article distributed under the terms of the Creative Commons Attribution License (CC BY). The use, distribution or reproduction in other forums is permitted, provided the original author(s) and the copyright owner(s) are credited and that the original publication in this journal is cited, in accordance with accepted academic practice. No use, distribution or reproduction is permitted which does not comply with these terms. 